\title{
A VIAGEM REDONDA BRASILEIRA E O ETERNO RETORNO DO MESMO ENTRE O DIREITO E A SOCIEDADE
}

\section{Giovanni de Araújo Nunes*}

Resumo: O artigo objetiva identificar em que medida a doutrina do eterno retorno pode auxiliar na compreensão, análise ou solução do problema da viagem redonda brasileira, bem como de que modo o Direito pode auxiliar na superação desse problema. Por meio do método dedutivo, baseado em investigações bibliográficas, constatou-se que reformas institucionais jurídicas são incapazes de resolver o problema da viagem redonda, bem assim o eterno retorno por si só. A saída para tanto estaria em uma transvaloração dos afetos, em vez de uma transvaloração dos valores segundo pensou Nietzsche. A pesquisa contribui para a Sociologia, Filosofia e Teoria do Direito.

Palavras-chave: Viagem redonda; eterno retorno do mesmo; patrimonialismo; estamento burocrático; transvaloração dos afetos.

\section{THE BRAZILIAN CYCLICAL TRAVEL AND THE ETERNAL RECURRENCE BETWEEN LAW AND SOCIETY}

\begin{abstract}
The article aims to identify how to comprehend, analyze and resolve the problem of the Brazilian cyclical travel by using the doctrine of eternal recurrence, as well as how to resolve this problem by using the Law. By means of the deductive method and bibliographic investigations, it was verified that juridical institutional reforms and the eternal recurrence are not capable to resolve the problem of the cyclical travel. The solution for that could be in a transvaluation of affects, instead of the transvaluation of values according to Nietzsche. The research contributes to Sociology, Philosophy and Theory of Law.
\end{abstract}

Keywords: Cyclical travel; eternal recurrence; patrimonialism; bureaucratic stratum; transvaluation of affects.

\section{INTRODUÇÃO}

É no último capítulo da obra Os donos do poder, de Raymundo Faoro, que o autor apresenta a ideia de viagem redonda: uma situação social e histórica na qual o tempo

\footnotetext{
* Mestrando em Ciência Jurídica pelo Programa de Pós-Graduação do Centro de Ciências Sociais Aplicadas, campus de Jacarezinho, da UENP, na área de concentração Teorias da Justiça: Justiça e Exclusão e linha de pesquisa Estado e Responsabilidade: Questões Críticas. Bolsista pela CAPES e pela Fundação Araucária. Graduado em Direito pela Universidade Estadual do Norte do Paraná (UENP), Centro de Ciências Sociais Aplicadas (CCSA). Estagiou no Ministério Público Federal, Procuradoria da República de Jacarezinho-PR. Pesquisador com ênfase nas áreas Sociologia Jurídica, Filosofia do Direito, Direito Administrativo, Direito Constitucional e Teoria do Direito. E-mail: giovanni.a.n.97@gmail.com.
} 
cronológico avança, mas o "tempo político" permanece o mesmo, se repetindo em espiral desde a colonização até os tempos da última edição da obra e de trabalhos posteriores do autor. Esse "tempo político", segundo Faoro, que permanece inalterado, independentemente das mudanças sociais que ocorrem na história, diz respeito, basicamente, à manutenção do patrimonialismo na estrutura do Estado brasileiro.

É possível perceber que a forma como Faoro compreendeu a ideia de viagem redonda em muito se assemelha à lógica contida no eterno retorno, de Friedrich Wilhelm Nietzsche. Em que pese a doutrina do eterno retorno do mesmo tenha uma conotação, ao mesmo tempo, ética e cosmológica, e a viagem redonda, por sua vez, constitua uma conclusão sociológica da pesquisa de Faoro acerca do patrimonialismo e do estamento burocrático na história do Brasil, as duas ideias guardam um ponto em comum: tanto o eterno retorno, quanto a viagem redonda trabalham com a ideia de um mesmo fenômeno se repetir em espiral, isto é, repetidamente, independentemente do transcorrer do tempo.

Diante desse contexto, o presente trabalho visa responder ao seguinte problema de pesquisa: em que medida a doutrina do eterno retorno do mesmo pode auxiliar na compreensão, análise ou solução do problema da viagem redonda? E de que modo o Direito pode auxiliar (ou não) na superação desse mesmo problema? A hipótese é de que o aspecto de uma espécie de imperativo ético que o eterno retorno representa pode auxiliar na resolução do problema da viagem redonda, e de que o Direito não seria suficiente para a sua superação, na medida em que a causa originária do patrimonialismo e do estamento burocrático seria um problema de ordem ética, e não jurídica. Será utilizado o método dedutivo, na medida em que a presente pesquisa partirá de argumentos teóricos gerais para chegar a conclusões formais com argumentos particulares e, assim, responder ao problema de pesquisa com o teste da hipótese. A técnica de pesquisa adotada será bibliográfica.

O primeiro capítulo se destinará a explicar os conceitos viagem redonda e eterno retorno para, no segundo capítulo, estabelecer um diálogo entre ambas as construções teóricas na busca por responder o problema de pesquisa proposto. Por fim, diante de todos os resultados obtidos até o segundo capítulo, será verificado de que modo o Direito pode auxiliar (ou não) na superação do problema do patrimonialismo na estrutura do Estado brasileiro.

\section{VIAGEM REDONDA E ETERNO RETORNO EM ANÁLISE TEÓRICA}


Segundo Brito, “o conceito de patrimonialismo é o fundamento teórico básico que permitiria compreender o que [Raymundo Faoro] chamou de a nossa 'viagem redonda', na qual o tempo cronológico passaria, mas o 'tempo político', por assim dizer, se repetiria incessantemente num ritmo circular" (BRITO, 2019, p. 53). Além disso, esse tempo político característico da viagem redonda apresenta uma nuance do ponto de vista democrático e uma nuance do ponto de vista do Estado de Direito, ou melhor, de um Estado que não é democrático e de um Estado que não é de Direito.

Ao longo da obra Os donos do poder, Raymundo Faoro demonstra como, por toda a história do Brasil, houve uma distância entre o Estado e a sociedade, no sentido tanto de esse Estado não atender aos interesses e necessidades da população, quanto no sentido de não haver controle popular desse Estado ou mesmo participação popular significativa. É um Estado, portanto, que se apresenta historicamente sobranceiro (em condição superior [a outro]; que domina, sobrepuja [o outro] pela altura; elevado, proeminente) à sociedade. Nas palavras do autor:

Quatro séculos de hesitações e de ação, de avanços e recuos, de grandeza e de vacilação serão a resposta de um passado teimosamente fixado na alma da nação. Estado e nação, governo e povo, dissociados e em velado antagonismo, marcham em trilhas próprias, num equívoco renovado todos os séculos, em contínua e ardente procura recíproca" (FAORO, 2012, p. 114).

A violação do elemento democrático do Estado brasileiro, segundo Faoro, pode apresentar duas nuances: a de um Estado que interfere diretamente sobre e em prejuízo da sociedade, e de uma sociedade que também não atua de forma efetivamente participativa em oposição a esse Estado.

Segundo Faoro (2012, p. 827): "Para evitar a participação popular, [o Estado] recorre, não raro, à mobilização das ruas, em manifestações que, atrás de si, só deixam o pó de palavras inconsequentes". "Já na estrutura normativamente constitucional, democrática na essência, os detentores do poder participam na formação das decisões estatais, mediante mecanismos de controle que atuam na participação popular" (FAORO, 2012, p. 829). Esses são exemplos trazidos por Faoro de como o Estado brasileiro incide antidemocraticamente sobre a sociedade.

Ao mesmo tempo, segundo o autor, não há uma postura popular em sentido efetivamente contrário a essas condições; em vez disso, o povo "oscila entre o parasitismo, a mobilização das passeatas sem participação política, e a nacionalização do poder, mais 
preocupado com os novos senhores, filhos do dinheiro e da subversão, do que com os comandantes do alto, paternais e, como o bom príncipe, dispensários ${ }^{1}$ de justiça e proteção" (FAORO, 2012, p. 837). Para Faoro, o povo seria "palavra e não realidade dos contestatários" (FAORO, 2012, p. 837).

Raymundo Faoro também trata do que conceituou como "estamento burocrático", outro elemento constitutivo da viagem redonda. Segundo Quintão (2011, p. 93), em interpretação de Faoro, o estamento burocrático seria, em linhas gerais, uma camada ou grupo de pessoas que dirige o Estado orientando as técnicas impessoais, objetivas e racionais da burocracia estatal em benefício de seus próprios interesses. No espectro político, nota-se que o estamento burocrático atua, pois, em sentido contrário à democracia, posto que serve a uma minoria política privilegiada em detrimento da coletividade (BRITO, 2019, p. 72).

\begin{abstract}
Para Faoro, portador de uma visão negativa acerca da nossa formação, a caracterização do Estado brasileiro como patrimonial-estamental significaria um percurso na história em que as maiorias fracassaram em seus objetivos de "controlar, vigiar, nacionalizar os poderes do Estado" (grifos no original), ficando o povo destituído da soberania. O argumento assume cores fortes: "o Brasil, malgrado suas instituições, não logrou sequer entrar no caminho da nacionalização do poder minoritário", e, desse modo, a maioria, sem meios para expressar a sua vontade na esfera pública, "nem a revolução lhe é deixada, usurpada pelas baionetas, que a substituem, com elegância, pelo golpe de Estado" (VIANNA in BOTELHO; SCHWARCZ, 2009, p. 368).
\end{abstract}

Outro elemento característico da estagnação do tempo político da viagem redonda diz respeito ao fato de que o Estado brasileiro, em que pese adotar formalmente um status de Estado moderno, na prática se apresenta avesso aos valores da burocracia moderna, como a impessoalidade e a racionalidade. É um Estado apenas formalmente moderno. E a figura trazida por Faoro que melhor expressa essa condição é justamente o estamento burocrático. Conforme já apontado, é burocrático porque "monopoliza as técnicas da administração da coisa pública", mas também é estamento, porque "se refere a um grupo social particular, com suas próprias regras de recrutamento, e seus mecanismos próprios de exclusão" (QUINTÃO, 2011, p. 93). Basicamente, o estamento burocrático age pelos seus próprios interesses pessoalidade - e em um âmbito que teria de ser impessoal e dotado de racionalidade jurídica: a burocracia da Administração Pública:

\footnotetext{
${ }^{1}$ Segundo o dicionário Houaiss, "dispensário" significa: "instituição beneficente que atende doentes pobres" (HOUAISS, 2010, p. 264).
} 


\begin{abstract}
Não impera a burocracia, a camada profissional que assegura o funcionamento do governo e da administração (Berufsbeamtentum), mas o estamento político (Beamtenstand). A burocracia, como burocracia, é um aparelhamento neutro, em qualquer tipo de Estado, ou sob qualquer forma de poder. [...]. Não se converte, o estamento político, entretanto, em governo da soberania popular, ajustando-se, no máximo, à autocracia com técnicas democráticas. [...], o governo arma, sobre o equilíbrio das bases, o papel de árbitro, sem que se possa expandir na tirania aberta ou no despotismo sem medida e sem controle. [...]. O estamento burocrático comanda o ramo civil e militar da administração e, dessa base, com aparelhamento próprio, invade e dirige a esfera econômica, política e financeira (FAORO, 2012, p. $825)$.
\end{abstract}

Faoro identifica que o estamento burocrático se encontra dentro da lógica da viagem redonda como uma "camada [que] muda e se renova, mas não representa a nação, senão que, forçada pela lei do tempo, substitui moços por velhos, aptos por inaptos, num processo que cunha e nobilita os recém-vindos, imprimindo-lhes os seus valores" (FAORO, 2012, p. 824). A própria lógica de uma repetição incessante e infindável no tempo histórico da viagem redonda está, portanto, diretamente atrelada ao estamento burocrático, que muda e renova seu pessoal ao longo do tempo, mas permanece sempre com as mesmas características que o definem enquanto estamento burocrático

E "se um dia, ou uma noite, um demônio lhe aparecesse furtivamente em sua mais desolada solidão e dissesse: 'Esta vida, como você a está vivendo e já viveu, você terá de viver mais uma vez e por incontáveis vezes" "2 (NIETZSCHE, 2001, p. 194, tradução nossa), em uma indagação hipotética ao sociólogo brasileiro Raymundo Faoro, tendo em vista os problemas do patrimonialismo e do estamento burocrático no Brasil? Essa ideia, de viver reiteradamente uma mesma vida por infinitas vezes, apresenta a doutrina do eterno retorno do mesmo, do filósofo alemão Friedrich Wilhelm Nietzsche. Nota-se que tal lógica também se encaixa, de certo modo, na problemática faoriana da viagem redonda.

$\mathrm{Na}$ hipótese de Faoro ser indagado sobre a possibilidade de viver por incontáveis vezes a mesma vida enquanto ciente da historicidade do patrimonialismo e do estamento burocrático, bem como do fato de estes fenômenos permanecerem hodiernamente atuantes, Faoro - supostamente - imaginaria essa hipótese como algo já vivenciado e constatado por ele em sua obra; nas próprias palavras do autor, "um passado teimosamente fixado na alma da nação" age em prejuízo do Brasil desde a sua colonização (FAORO, 2012, p. 114).

\footnotetext{
${ }^{2}$ Traduzido de: "What if some day or night a demon were to steal into your loneliest loneliness and say to you: "This life as you now live it and have lived it you will have to live once again and innumerable times again [...]" (NIETZSCHE, 2001, p. 194).
} 
Como, então, interpretar a viagem redonda de Raymundo Faoro a partir da doutrina do eterno retorno do mesmo, de Friedrich Nietzsche?

O eterno retorno é, antes de tudo, uma doutrina cosmológica, uma ideia que apresenta uma nova cosmovisão em oposição e sucedâneo à visão cosmológica pautada no cristianismo, na moral e no conceito de verdade da filosofia, restando apenas o "nada: o abismo do nada" (REALE; ANTISERI, 2018, p. 249). Segundo essa forma de compreender cosmologicamente a vida e a realidade de tudo:

O mundo não avança de forma retilínea em direção de um fim (como crê o cristianismo), nem o seu devir é progresso (como pretende o historicismo hegeliano e pós-hegeliano), mas "todas as coisas eternamente retornam e nós com elas, e nós fomos já eternas vezes e todas as coisas conosco" (REALE; ANTISERI, 2018, p. 250).

Trata-se, portanto, de apresentar uma visão cosmológica que é também pautada na eternidade, assim como a visão cristã ocidental, mas cujo apelo ético "não estaria mais localizado num além-mundo, mas sim neste mundo terreno" (MELO NETO, 2017, p. 96). É a repetição eterna de uma mesma vida que passa a dar sentido a essa vida, e não a condenação ou a salvação eternas e a busca do que Nietzsche entende como uma negação da vida em prol de um além-mundo (MELO NETO, 2017, p. 96). Trata-se de:

[...] uma cosmovisão cíclica e não dualista [com a qual] Nietzsche vislumbrou a possibilidade de suprimir e substituir a concepção cosmológica dominante no Ocidente - esta, enraiada numa compreensão linear de tempo, no dualismo de mundos e na noção de um Deus que irá julgar e definir o destino de todos no além (MELO NETO, 2017, p. 95).

Vivendo-se e compreendendo-se a realidade de tal modo, na concepção de que "cada estado do cosmo se repetiria e condicionaria, necessariamente, o retorno sequencial de todos os mesmos estados do ciclo cósmico" (MELO NETO, 2017, p. 94), isso implica que não será o medo da condenação eterna ou a esperança de uma recompensa eterna que orientarão as ações humanas de um sujeito, mas, sim, o fato de que, se não fizer aquilo que é importante e tem sentido a esse sujeito, este terá de viver eternamente a mesma vida de sofrimento. Cabe ao sujeito decidir como viverá sua vida eternamente. É o valor da própria vida, portanto, que determina como a vida será vivida, e não a negação dessa vida em busca de um além-viver ${ }^{3}$. É

\footnotetext{
${ }^{3}$ Ao eterno retorno do mesmo está intimamente ligada a noção de amor fati (amor aos fatos), de Nietzsche, na medida em que essa força ou vontade criadora implica aceitar sem restrições tudo que ocorre ao redor do sujeito (MARTON, 2016, p. 27).
} 
uma doutrina que ensina "a eternidade de cada instante terreno, [redirecionando as ações humanas] à afirmação da vida terrena" (MELO NETO, 2017, p. 98).

O ser humano, para Nietzsche, é fundamentalmente movido por impulsos e é a essa natureza que se deve dar vasão. Nas palavras de Benedito Nunes (2019, p. 84) - em relação aos impulsos do ser humano segundo Nietzsche:

Seu destino depende, pois, da função que der aos impulsos com que a natureza o dotou, e aos quais estão subordinadas a consciência, a moral, a razão e a lógica. Nesse sentido, é lícito falar-se numa autoformação do homem. Para Nietzsche, no entanto, esse processo [...] é fundamentalmente natural, e, não obstante produzir consideráveis efeitos sociais e históricos, obedece ao dinamismo biológico e psíquico dos instintos primários.

E continua:

\begin{abstract}
Os instintos primários, que têm na dominação o seu objetivo natural, podem ser desviados para outros fins, considerados nobres e superiores. Segundo Nietzsche, tais fins são derivativos antinaturais, que apenas cerceiam a expansão dos impulsos ou conseguem mudar-lhes a direção primitiva. Assim, a concepção trágica de Nietzsche, para a qual a vida é instinto e o instinto poder, constitui uma concepção de fundo irracionalista, não só por admitir que a razão deriva da vida, como também porque nos ensina que a razão é um poder eficaz, mas secundário, o qual, via de regra, interfere, de maneira negativa, no processo de autoformatação do homem (NUNES, 2019, p. 85).
\end{abstract}

A contenção dos impulsos para Nietzsche configura, pois, um movimento antinatural na natureza do ser humano. O instinto humano apresenta a dominação como o seu objetivo natural e quaisquer desvios desse propósito inato para fins mais nobres, valoráveis, superiores, são antinaturais, pois cerceiam, limitam ou mudam a direção de impulsos primitivos do homem. Mais uma vez citando Benedito Nunes, para Nietzsche, o ser humano é: “Animal sadio impulsivo e demasiado humano, imoralista e extremamente responsável, escolhendo-se a si mesmo por meio de atos que não se pautam pela mediocridade das virtudes estabelecidas [...]"; este é o Além-do-homem, segundo Nietzsche (NUNES, 2019, p. 89). Deve ser "pessoal em todos os seus atos" (NUNES, 2019, p. 89).

\title{
3 VIAGEM REDONDA E ETERNO RETORNO EM DIÁLOGO
}

Nesse sentido, dentro de uma acepção ética de aceitação ébria da vida e de não negação ou qualquer forma de contenção ou redirecionamento dos impulsos, o eterno retorno do mesmo apresenta duas direções possíveis que podem ou não ser favoráveis à resolução do problema identificado por Faoro na viagem redonda. 
O primeiro ponto a se considerar é que "não obstante produzir consideráveis efeitos sociais e históricos, [o eterno retorno] obedece ao dinamismo biológico e psíquico dos instintos primários" do ser humano (NUNES, 2019, p. 84). Desse modo, o eterno retorno tem como foco tratar daquilo que tem valor, importância e atende às vontades e impulsos de cada ser humano. A conversa hipotética de um demônio que apresenta a um indivíduo a doutrina do eterno retorno do mesmo é focada num sujeito, e não imaginada sob uma perspectiva central de que somente a realidade em volta desse sujeito se repetirá eternamente - como é o caso da viagem redonda.

A partir de sua visão cosmológica, Nietzsche parte de uma ideia segundo a qual as forças existentes no cosmo são limitadas e não eternas, e a proposição do eterno retorno tem por base que tudo se repetirá igualmente por infinitas vezes, tanto o sujeito e suas ações, quanto o mundo e a realidade a sua volta. Porém, a pretensão do eterno retorno não é para que o sujeito que escutou o demônio deixe de se atentar para si mesmo a fim de se voltar para a realidade a sua volta e, então, buscar mudá-la ou com ela se relacionar de algum modo específico porque eternamente isso irá se repetir.

O intuito da doutrina do eterno retorno do mesmo é que o sujeito caia por si e se dê conta de que, se não viver pelas suas vontades e seus impulsos, estará preso a uma vida sem sentido eternamente. E Nietzsche não é um filósofo social, com a pretensão de trazer noções de civismo e bem comum - ele está, na verdade, longe disso. "Não sou um ser humano, sou dinamite" (NIETZSCHE, 2013, p. 173), já disse o autor em Ecce Homo. Desse modo, a aplicação do eterno retorno aos agentes do Estado brasileiro e à sociedade na viagem redonda, como um todo, a fim de que passem pelo processo de "conversar com o demônio" de A Gaia Ciência (NIETZSCHE, 2001, p. 194), pode não resultar em uma reanálise dos problemas do patrimonialismo e do estamento burocrático para uma possível mudança, ou ao menos a sua busca.

Todavia, pode não ser de tal forma. E diz-se "pode-se" porque, valendo-se do eterno retorno, o sujeito se volta para suas vontades, para seus impulsos. E se a sua vontade for justamente a de contribuir para o bem comum da sociedade brasileira e, desse modo, buscar de alguma forma lidar com as questões do patrimonialismo e do estamento burocrático na viagem redonda do Brasil? Talvez a saída seja uma reinterpretação do eterno retorno do mesmo; para não negar os afetos e impulsos, mas também não os afirmar e a eles se entregar independentemente de tudo. Talvez a saída seja uma "transvaloração dos afetos" e não uma 
“transvaloração dos valores”, como projetou Nietzsche (MELO NETO, 2017, p. 95). Talvez a saída deva ser essa, pois nem todos os impulsos são benéficos, seja ao próprio indivíduo que deles desfruta, seja - como é na maioria das vezes - às pessoas a sua volta e à toda a sociedade. E como o próprio autor alemão reconheceu, nas palavras de Benedito Nunes (2019, pp. 84-85), o processo de autoformação do homem obedece a instintos primários, que têm na dominação o seu objetivo natural; e foi justamente a dominação, um Estado sobranceiro à sociedade, segundo Raymundo Faoro, que implicou a viagem redonda da história brasileira, de patrimonialismo e de estamento burocrático.

A razão não se opõe à paixão e muito menos é capaz de se apresentar contrária à vontade ou controlá-la. Tendo por base a filosofia de Hume, pode-se afirmar que, sozinha, a razão é incapaz de gerar ato de vontade e, por isso, é incapaz de influenciar de forma direta a ação e a vontade - diz-se "de forma direta" porque indiretamente a razão influencia a vontade, conforme será demonstrado mais à frente. Mas fato é que a razão, sozinha, "é igualmente incapaz de impedir uma volição ou de disputar nossa preferência com qualquer paixão ou emoção" (HUME, 2009, p. 450). A vontade e a ação são influenciadas pelas paixões. Na verdade, a vontade é a manifestação consciente no indivíduo de suas paixões e, consequentemente, tem-se ações voltadas à satisfação de tal vontade. E as paixões são moldadas conforme o espectro da expectativa de auferir dor ou prazer (SILVA in NEUTZLING, 2011, p. 17; ALMEIDA, 2007, p. 84).

Nesse quadro, o único papel da razão seria dirigir os atos decorrentes da vontade dos indivíduos. Veja, a razão não conduz a vontade, pois esta é fruto único e exclusivo das paixões. A razão seria apenas empregada como meio de identificação e qualificação dos meios mais adequados para a satisfação dessa vontade. Segundo Hume: "a única possibilidade de a razão ter esse efeito de impedir a volição seria conferindo um impulso em direção contrária à de nossa paixão" (HUME, 2009, p. 450).

Porém, não é possível que a razão gere impulsos, paixões ou vontades. Somente paixão gera vontade. E, por conseguinte, muito menos poderá, a razão, impedir uma vontade, se sequer pode a razão gerá-la. Somente não há vontade quando não há paixão. Porém, não há como o ser humano se ver destituído de paixões. A saída, portanto, seria o surgimento de paixões no indivíduo que sejam capazes de afastar e impedir outras paixões de se manifestarem. Somente, portanto, paixões são capazes de se opor a paixões. O contrário da paixão é outra paixão, e não uma razão que se pretenda se opor à paixão. 
“[...] quando nos referimos ao combate entre paixão e razão, não estamos falando de uma maneira filosófica e rigorosa" (HUME, 2009, p.451), o que significa dizer que a oposição paixão/razão não existe na medida em que cada uma delas possui oposições internas as quais são incomparáveis entre si. A razão envolve a oposição verdade/falsidade, enquanto as paixões se referem à oposição bom/mal. Razão e paixão, portanto, são contrárias não como polos de uma mesma relação que se opõem; são elas, na verdade, constituintes de relações próprias, dentro das quais, nestas sim, há polos opositores. Na relação da razão, verdade se opõe à falsidade, assim como o bom se opõe ao mal na relação das paixões. Não há, portanto, uma oposição entre elas; trata-se, mais precisamente, de elementos que são incomparáveis (HUME, 2009, p. 451).

Quanto a raciocínios que induzem a erros e, portanto, geram falsidade, diz Hume que "uma paixão tem de ser acompanhada de algum juízo falso para ser contrária à razão; e mesmo então, não é propriamente a paixão que é contrária à razão, mas o juízo" (HUME, 2009, p.452). Portanto, o raciocínio é que implicou em erro, não as paixões. Ou um raciocínio irá gerar uma constatação, a partir da qual se originará uma paixão específica; ou já há uma paixão específica e, a partir dela, a razão conduzirá aos meios mais adequados para satisfazer a vontade decorrente dessa paixão. Se esse raciocínio implicou a constatação indevida da realidade e a paixão daí oriunda se pautou numa falsidade - por exemplo, acreditar que há um animal feroz à solta e, por isso, se armar para combatê-lo, quando, na verdade, ele não existe -, há um problema com o juízo, o raciocínio tido, que foi falso, mas não um problema com a paixão. Do mesmo modo, se existe a vontade de se consumir determinado alimento, estabelece-se um raciocínio para conduzir o indivíduo a determinado estabelecimento para consumir esse alimento e, então, depara-se com a constatação de que, na verdade, errou-se o destino do estabelecimento, o problema aqui não decorre da paixão, mas, sim, de um raciocínio falho. Nesses dois casos não houve oposição entre paixão e razão, mas a ocorrência de falsos juízos da realidade.

Essa constatação de Hume segundo a qual não há uma prevalência da razão na condução das ações humanas, bem como no controle de seus juízos de valor moral, se fez corroborada pelo que a neurociência, hodiernamente, identificou como pressupostos determinantes da ação humana e da análise moral do ser humano acerca da realidade.

Em seu artigo "Emoção, juízo moral e razão: Damásio e a crítica do racionalismo ético", Francisco Jozivan Guedes de Lima e Nythamar Hilario de Oliveira (2019) apresentam 
como, por meio da teoria neurocientífica de Damásio, é possível identificar não uma prevalência da razão no comando das condutas humanas e em seus juízos de valor moral, em detrimento das emoções, mas, na verdade, que estas é que exercem uma influência e comando primeiro sobre as ações humanas e juízos morais. Os autores, Lima e Oliveira (2019, p. 18), chegam até mesmo a reconhecer uma correspondência entre o pensamento de Hume e o que foi constatado nos experimentos de Damásio e registrado em sua teoria.

Damásio efetua experimentos com dois de seus pacientes, os quais, ambos, sofreram acidentes que prejudicaram, em alguma medida, a parte do seus cérebros denominada de “córtex pré-frontal”, região responsável pela gestão das emoções humanas. Após o acidente, ambos os pacientes analisados por Damásio apresentaram mudanças drásticas de comportamento relacionadas à sua tomada de decisões e, especificamente em relação a um dos pacientes, teve-se alterado por completo o seu padrão de moralidade. Antes do acidente, o paciente denominado Cage era reconhecido como um homem de integridade, pontual e respeitoso; posteriormente, todavia, tornou-se indisciplinado e obsceno, inclusive ao ponto de as mulheres serem aconselhadas a se afastarem dele (LIMA; OLIVEIRA, 2019, p. 19). Quanto a Elliot, o outro paciente, suas emoções ficaram neutras, de modo que ele passou a não esboçar reações nem positivas, nem negativas diante de situações que teriam de provocarlhe tais sentimentos:

[...] colocaram imagens de edifícios caindo, pessoas ensanguentadas em acidentes, outras se afogando, casas pegando fogo, mas Elliot continuava impassível. Ele tinha consciência que as imagens eram fortes, mas não conseguia exprimir sentimentos e emoções acerca das mesmas; os seus marcadores somáticos não eram ativados (LIMA; OLIVEIRA, 2019, p. 20).

"[Elliot] tinha consciência que as imagens eram fortes", assim como também Cage possuía consciência disso, ou seja, havia um funcionamento racional pleno no cérebro desses dois pacientes a respeito do que estava acontecendo a sua volta. Os seus cérebros estavam em perfeito funcionamento. Porém, bastou que a área do cérebro afeta as suas emoções fosse lesionada para que a tomada de decisão dos pacientes e sua percepção moral dos fatos fossem alteradas:

Gage e Elliot, depois da lesão cerebral, mantiveram intactas funções diversas no que diz respeito à linguagem, à cognição, e aos movimentos corporais, mas tiveram prejudicada a região do cérebro correspondente ao campo das emoções, e isso foi o suficiente para desestabilizar as suas tomadas de decisões em questões concretas da vida cotidiana, sem contar as questões morais mais complexas (LIMA; OLIVEIRA, 2019, p. 20). 
Tudo isso demonstra que as paixões e os afetos não são opostos à razão, mas atuam em âmbitos diversos. Além disso, tudo isso demonstra que a preocupação com a mudança de comportamentos do ponto de vista ético, e apenas tendo em vista a racionalidade da conduta, não serve para modificar condutas no sentido de as tornar mais ou menos éticas. A pesquisa retratada acima demonstrou que partes do cérebro relacionadas às emoções, quando prejudicadas, prejudicam também a tomada de decisões éticas.

O comportamento humano, portanto, para ser ético, depende de uma transvaloração de afetos, e não de uma transvaloração dos valores, ou seja, não é da concepção por parte de um indivíduo de algo como valorável ou não que suas condutas se moldaram de uma perspectiva ética. É preciso, além do reconhecimento de questões como valores ou não valores, que haja afetos nos indivíduos em prol da afirmação concreta desses valores em suas condutas para que, então, haja de fato uma mudança ética no comportamento dos indivíduos.

\section{VIAGEM REDONDA E ETERNO RETORNO ENTRE O DIREITO $E$ A SOCIEDADE}

Em A substancialidade dos procedimentos oligárquicos no brasil entre 1995 e 1998: as análises de Faoro, Maria José de Rezende faz uma análise de textos de Faoro em que ele externa sua visão acerca das reformas administrativas buscadas no Brasil ao início da década de 1990. Ela aponta que, em textos mais recentes do autor, Raymundo Faoro demonstra como, nos últimos anos do século XX, década de 1990, mantiveram-se presentes as mesmas estruturas patrimonialistas e estamentais que historicamente existiram no Estado e na sociedade brasileiros (REZENDE, 2011, p. 183).

Faoro não reconheceu, por isso, que inexistiram avanços constitucionais e democráticos com Constituição de 1988 (REZENDE, 2011, p. 185), porém, o autor alertava, “mediante uma análise minuciosa do período pós-promulgação, que a efetivação dos direitos constantes na nova Carta passava pelo desbloqueio da ação política daqueles interessados em fazer valer, de fato, os seus direitos". Nesse contexto, Faoro entendia os brasileiros somente seriam cidadãos em concreto se os setores subalternos da sociedade lutassem para que seus direitos na Constituição fossem, paulatinamente, implantados (REZENDE, 2011, p. 187).

Maria José de Rezende aponta, então, que, para Faoro, não seria uma questão de novas leis e atos normativos a solução para o problema do patrimonialismo na sociedade 
brasileira; seria, ao contrário, uma questão de efetivação dos atos normativos já existentes (REZENDE, 2011, p. 187). Todavia, não se deve pressupor a partir disso que Faoro reconheceu que as normas do direito brasileiro alcançaram um nível de satisfação em quesito de justiça e adequação à realidade brasileira. $\mathrm{O}$ ponto aqui não é esse. Faoro conclui pela necessidade de se efetivar direitos já existentes para além de sua mera asseguração no ordenamento jurídico.

Essa conclusão prática muito tem a ver com o que já havia sido produzido pelo autor em sua obra Os donos do poder. É possível observar, principalmente no último capítulo da obra, denominado "A Viagem Redonda", que todos os atributos de um Estado de Direito que foram incorporados na sociedade brasileira acabaram por ser afetados pelas estruturas patrimonialistas e estamentais já existentes no Brasil (FAORO, 2012, p. 825, 829).

A solução para o problema da viagem redonda não envolveria, portanto, a implementação de novas estruturas normativas no Direito brasileiro, reformas institucionais e administrativas. Claro, Faoro não nega a necessidade de reformas quando as mesmas são necessárias. Inclusive, conforme já apontado, o autor reconheceu a tamanha importância da Constituição de 1988, bem como lutou pela redemocratização do Brasil, enquanto presidente do Conselho Federal da OAB (MARCHESINI JUNIOR, 2004, p. 17-18).

Porém, o ponto a que se deve chegar a respeito disso é que não bastam reformas institucionais e normativas para resolver o problema da viagem redonda. São insuficientes tais escopos se, quando alcançados, as estruturas sociais, estatais e políticas continuam moldadas de modo a obstaculizar a efetivação dos direitos e institucionalizações que foram alcançados, em tese, com o propósito de assegurar direitos constitucionais, inclusive com o propósito de diretamente se oporem à confusão do público com o privado.

[...] a ideia de que uma reforma política poderia resolver os grandes problemas da sociedade brasileira é mais difícil de ter vista no pensamento do nosso autor, pois o problema do país é justamente o predomínio do político sobre a sociedade, quando deveria ser o inverso. Neste sentido, uma reforma política poderia abrir caminho para uma modernização, se vinda de cima e sem a participação popular. A questão do "meio" das reformas é importante para o nosso autor, pois nisto se encontraria o cerne da distinção entre "modernidade" e "modernização" (BRITO, 2019, p. 252).

"Modernização", aqui, significa, para Faoro, o processo de implementação dos pressupostos de um Estado moderno de Direito, mas que se dá "por cima", isto é, por meio da ideologia e da coação e, portanto, pelos próprios detentores do poder. Por conta disso, apresenta-se como uma política de mudança inócua, que apenas confirma o sistema de poder 
já existente em vez de gerar uma mudança efetiva na sociedade e nas instituições. Têm-se, assim, os pressupostos de um Estado moderno de Direito, mas sob a vontade política de um grupo de poder já ali presente e que utiliza as próprias novas estruturas de Estado de Direito para se privilegiar, bem como beneficiar demais grupos dominantes da sociedade (VIANNA in BOTELHO et. SCHWARCZ, 2009, p. 375-376).

Já a "modernidade" abarca toda a sociedade e todas as classes, num processo que não vem "de cima para baixo", numa ação organizada pelos próprios detentores do poder; ao contrário disso, é um processo comandado pela própria sociedade que, “de baixo”, se organiza e busca as mudanças para implementar a estrutura de um Estado de Direito diretamente em oposição aos detentores do poder (VIANNA in BOTELHO et. SCHWARCZ, 2009, p. 375- p. 376).

O último capítulo de Os donos do poder parece negar uma saída jurídica ou institucional ao problema do patrimonialismo, uma vez que todas as reformas já feitas conduziram ao mesmo lugar. Tendo acontecido no Brasil o que Faoro denominou de "modernização" em vez do que ele entende como "modernidade", reformas jurídicas e institucionais, ainda que formalmente necessárias, acabaram sempre por resultar na manutenção do patrimonialismo e do estamento burocrático ao longo da história.

A solução, portanto, a esses problemas parece ser de uma mudança no campo concreto em que se assenta a institucionalização, não uma nova institucionalização. Reformas necessárias devem ser buscadas, assim como o foi a redemocratização com a Constituição de 1988, expressamente defendida por Faoro, tanto em palavras, quanto em atos. Todavia, isso não é o suficiente. É preciso uma mudança concreta, no campo da ética e dos costumes da sociedade, voltada à valorização e reconhecimento do bem comum e de preocupação com a coisa pública. Somente assim esta será privada e afastada da inserção de interesses particularistas que se sobrepõem aos interesses público e da coletividade.

Percebe-se que o problema não é uma questão de institucionalização para fins de romper com os problemas sociais e institucionais brasileiros, mas, sim, mudar a préinstitucionalização que obstaculiza a concretização de reformas de quaisquer âmbitos na sociedade brasileira. A ausência de mudanças concretas na realidade implica o que o autor gaúcho denomina de modernização, em oposição à modernidade. A partir da sociologia de Faoro, constata-se que não importa as reformas institucionais que se insurjam na estrutura de Estado, todas elas acabam por se macular com o patrimonialismo e o estamento burocrático e, 
por conseguinte, mantem-se sempre a mesma estrutura de confusão entre o público e o privado.

Seguindo essa toada, o próprio Raymundo Faoro, no capítulo destinado a tratar da viagem redonda, cita Karl Loewenstein e sua classificação ontológica da Constituição, teoria que possibilita identificar diversas possibilidades de uma ordem constitucional se relacionar com a sociedade no sentido de essa ordem jurídico-constitucional ter ou não correspondência, em quesito de concretização, na realidade fática (FAORO, 2012, p. 826, 829). Utilizando tal classificação, Faoro conclui que os textos constitucionais brasileiros foram "em regra escritos semânticos ou nominais sem correspondência com o mundo que regem” (FAORO, 2012, p. 826).

As constituições semânticas são, para Karl Loewenstein, em linhas gerais, aquelas que prescrevem normas em benefício exclusivo dos detentores de fato do poder político, que são aqueles que dispõem do aparato coercitivo do poder estatal e que, no caso, o utilizam em benefício próprio. Tais constituições, em vez de limitarem o poder político, são instrumentos que visam estabilizar e eternizar os detentores de poder de fato na direção do Estado. São as constituições típicas dos Estados autoritários (LOEWENSTEIN, 1979, p. 218-219).

Já as constituições nominais ou nominalistas são, em linhas gerais, aquelas que, em que pese tenham validade jurídica, o processo político que elas regulamentam ainda não se adaptou a tais normas, tendo um descumprimento generalizado de tal ordem jurídica constitucional. Nas palavras de Loewenstein, essas constituições carecem de "realidade existencial" (LOEWENSTEIN, 1979, p. 218).

Os pressupostos sociais e econômicos existentes na realidade social e institucional regida por uma Constituição nominalista não possibilitam que haja uma observância generalizada das normas constitucionais na realidade concreta, notadamente no processo político de poder. A realidade concreta, nesse sentido, acaba por impedir que haja uma integração generalizada das normas constitucionais com a dinâmica da vida política. Seria uma espécie de Constituição prematura e, por isso, Kar Loewenstein entende que, sob sua vigência, ainda existe certa esperança de que os detentores do poder e a sociedade como um todo venham a possibilitar que a realidade fática, em algum futuro, corresponda à ordem jurídica constitucional. A Constituição nominalista teria, portanto, uma função educativa e, como escopo, que em algum tempo futuro seja observada de forma generalizada pela sociedade e pelas estruturas políticas de poder (LOEWENSTEIN, 1979, p. 218). Nas palavras 
de Marcelo Neves (2011, p. 107): “[Na Constituição nominalista] há uma discrepância radical entre práxis do poder e disposições constitucionais, um bloqueio político da concretização constitucional, obstaculizador da autonomia operativa do sistema jurídico".

A classificação ontológica da Constituição, de Karl Loewenstein, coligada às conclusões de Faoro no capítulo "A Viagem Redonda”, permite um vislumbre da perspectiva de "interesse público" delineada por León Duguit. Segundo esse autor, não há vontade do Estado, vontade da coletividade, interesse público, poder público. São todas abstrações que, materialmente, decorrem, em verdade, da expressão das vontades individuais daqueles que administram e gerem a máquina Estatal: “[...] los gobernantes no son sino individuos como los demás [...]" (DUGUIT, 2005, p. 59); e "El poder público es una ficción. Es una noción sin valor, que es preciso desterrar de toda construcción positiva del derecho público. Esta negación, como se acaba de ver, es consecuencia lógica de la negación misma de la personalidad de la nación y de la voluntad nacional” (DUGUIT, 2005, p. 59).

Por essa razão, é inevitável que a vontade individual dos agentes do Estado se faça presente em suas manifestações e atos. Os conceitos de vontade nacional, vontade coletiva, interesse público e outros são utilizados, segundo Duguit, como uma forma de os detentores do poder imporem este poder de fato, mas fazendo-se crer que se trata de um poder de direito: "[...] esta palabra no se emplea por las gentes que detentan el poder sino como un medio cómodo de imponer este poder, haciendo creer que es un poder de derecho, cuando no es más que un poder de hecho" (DUGUIT, 2005, p. 59).

Isso não significa, todavia, que Duguit entende ser devida a inexistência do Estado (anarquia), muito menos que nega a importância da ordem jurídica se impondo sobre as ações dos agentes públicos e da sociedade como um todo. Trata-se, primeiramente, de uma inevitabilidade, de uma ocorrência natural nas sociedades em que haja aqueles que governam e aqueles que são governados - o que também não significa que Duguit entende como legítima qualquer forma de governo sobre os governados, conforme se verá mais adiante:

[...] la existencia de todo gobierno es la forzosa consecuencia de la diferenciación que se produce naturalmente en toda sociedad entre los fuertes y los débiles. Negar este hecho es negar la evidencia, y toda doctrina anarquista propiamente dicha va contra la evidencia de los hechos.

Nuestra doctrina es cabalmente la opuesta. Decimos nosotros: la potestad gobernante existe y no puede menos existir. Solamente negamos que sea un derecho. Afirmamos que los individuos que detentan esta potestad gobernante detentan una potestad o un poder de hecho, y no un poder de derecho. Al decir que no poseen la potestad pública, queremos decir que no tienen el derecho de formular órdenes, y que las manifestaciones de su voluntad no se imponen como tales a los gobernados (DUGUIT, 2005, p. 59). 
Além disso, León Duguit entende que o poder dos governantes é de fato e não de direito. É diferente afirmar que "o poder é exercido sob o Direito" de se afirmar que há "o direito de exercer um poder". Somando isso ao que o autor diz mais à frente, é possível compreender que a intenção do texto é justamente estabelecer uma distinção entre ter um poder de Direito e exercer o poder sob o Direito. Duguit reconhece a importância do Direito, chegando a afirmar que: "Si, el Estado es fuerza, pero fuerza subordinada a una regla de derecho superior a él, fuerza que no se impone legítimamente sino cuando se ejercita conforme a esta misma regla de derecho. Si el derecho sin la fuerza es la impotencia, la fuerza sin el derecho es la barbarie" (DUGUIT, 2005, p. 63).

Nota-se, aqui, entretanto, que Duguit não afirma que o exercício da força é um exercício de direito; trata-se de um exercício de fato, mas que está e que deve estar subordinado à ordem jurídica. Afirmar que o poder é de direito é colocar o poder acima, sobre o direito, atuando o direito como um mero legitimador desse poder. De fato, tanto o "poder de direito", quanto o "poder sob o direito" apresentam o direito como legitimador do poder, porém, no segundo caso, trata-se de um exercício de poder estrito nos limites traçados pelo direito. Isso fica mais claro quando, logo em seguida, Duguit expõe que:

\begin{abstract}
Lo que de esto se infiere es que las declaraciones de la voluntad de los gobernantes no tienen valor más que en la medida en que se hallan conformes con la regla de derecho de que hemos determinado el fundamento en el $\S 7$, y que se impone a todos los miembros de una misma sociedad, viniendo a ser como la armadura de esta sociedad misma [...]. El acto administrativo, finalmente, en su aspecto dispositivo, no aparecerá revestido de un carácter proprio y genuino por el hecho de emanar de los gobernados e de sus agentes: el acto administrativo se surtirá efecto sino cuando las condiciones normales y generales de todo acto jurídico aparezcan reunidas y haya desaparecido así el carácter regalista de la administración (DUGUIT, 2005, p. $59-60)$.
\end{abstract}

É dizer que, em linhas gerais: "Las manifestaciones de voluntad de los gobernantes tienen un valor social indudablemente; pero en tanto que se conforman a la regla social; al derecho objetivo, y tan sólo en este aspecto y dentro de estos límites” (DUGUIT, 2005, p. 60, grifo do autor).

Na conjunção teórica das ideias de Faoro, Loewenstein e Duguit trazidas acima, é possível se chegar à constatação de que o problema do patrimonialismo na sociedade, e em especial na sociedade brasileira, decorre de uma predominância da realidade fática sobre a ordem jurídica no sentido de a descumprir, de a excepcionalizar. A solução, portanto, para o 
problema do patrimonialismo na sociedade brasileira não estaria localizada (apenas) em reformas normativo-jurídicas e institucionais. Para se romper com a confusão generalizada na sociedade brasileira do público com o privado, é necessário que, na relação lícito/ilícito, o polo da ilicitude não se sobreponha à ordem jurídica, o que acontece não apenas quando já se tem uma ordem jurídica estabelecida e, portanto, o código-binário lícito/ilícito validamente vigente em sociedade, mas quando outros códigos binários não afetam negativamente a autonomia do sistema jurídico, a exemplo dos códigos poder/não-poder, ter/não-ter ${ }^{4}$.

O direito não deixa de ser necessário, e os autores apresentados acima não negam isso; ao contrário, consideram imprescindível a ordem jurídica, o controle estatal dos interesses privados dos detentores de poder político e a importância da democracia para a ordem social. Entretanto, no fundo, como bem delineia Duguit, interesse público, poder público, vontade da coletividade são todas abstrações que, no fundo, quando manifestadas, perpassam pelas mãos de indivíduos, de pessoas cujas condutas são orientadas por uma série de outros fatores para além da ordem jurídica. É preciso que uma mudança ética e comportamental generalizada se irrompa da sociedade brasileira para que a ordem jurídica hoje vigente possa ser efetivada e, então, seus direitos e garantias fundamentais tenham uma correspondência generalizada em quesito de observância por parte da sociedade.

\section{CONCLUSÃO}

Num primeiro momento, constatou-se que a aplicação do eterno retorno para auxiliar na compreensão, análise ou resolução do problema da viagem redonda pode não resultar em uma solução aos problemas do patrimonialismo e do estamento burocrático. Isso porque o

\footnotetext{
${ }^{4} \mathrm{O}$ código lícito/ilícito se trata de um dos conceitos da teoria dos sistemas de Niklas Luhmann. Os sistemas da sociedade possuem estruturas internas próprias que tornam um sistema diverso do outro, mas isso em virtude de uma identidade comum que é invariável: os códigos binários de referência. Tais códigos são constituídos por valores opostos, um positivo e um negativo. No caso da ciência, tem-se verdadeira/falsa teoria; na política, governo/oposição; na economia, ter/não-ter propriedade; etc.; e, no caso do sistema jurídico moderno, esse código é o lícito/ilícito. (SILVA, 2016, p. 104, 106). "A positivação do direito na sociedade moderna implica [...] o controle do código-diferença 'lícito/ilícito' exclusivamente pelo sistema jurídico, o qual, desse modo, adquire seu fechamento operacional"; enquanto, na sociedade pré-moderna, "o princípio de diferenciação se baseava numa distinção entre superior e inferior" e "apenas o sistema supremo, o político, tinha a autonomia autorreferencial. O direito permanecia supradeterminado pela política e pelo ideário moral estático, políticolegitimador, não dispondo, exclusivamente, de um código-diferença 'sim/não' específico" (NEVES, 2018, p. 47). Nos países de modernidade periférica - como é o caso do Brasil -, há uma interpenetração destrutiva dos códigos binários de outros sistemas (governo/oposição; ter/não-ter; poder/não-poder etc.), ou de sistemas regionais jurídico-políticos da modernidade central, em detrimento da autonomia (reprodução autopoiética) do sistema jurídico e, consequentemente, do uso de seu código-binário lícito/ilícito em sua abertura cognitiva com fechamento normativo, sendo que, em alguns momentos, o movimento inverso também ocorre (NEVES, 1994, p. 264; NEVES, 2011, p. 93, 135, 149, 155; NEVES, 2018, p. 108).
} 
foco da doutrina do eterno retorno do mesmo é que o sujeito se dê conta de que, caso não viva por suas vontades e impulsos, estará preso a uma vida sem sentido num ciclo eterno de repetições. O problema é que esses impulsos e vontades podem não ser avessos ao patrimonialismo e ao estamento burocrático, mas o contrário: podem ser suas causas e até mesmo impulsos e vontades patrimonialistas. E Nietzsche não busca mudanças sociais, com pretensões cívicas e de bem comum; ao contrário, ele busca a própria amoralidade. A hipótese mostrou-se, portanto, parcialmente válida, na medida em que o aspecto de uma espécie de imperativo ético que apresenta o eterno retorno tanto pode, como não pode auxiliar na resolução do problema da viagem redonda.

Ao aplicar o eterno retorno do mesmo, busca-se a valorização da própria vida e dos impulsos, e estes tanto podem ser pejorativos quanto positivos em relação ao cuidado da coisa pública e resolução dos problemas, patrimonialismo e estamento burocrático. Isso sem contar que, segundo Nietzsche, os impulsos humanos têm na dominação o seu objetivo natural, o que acaba por ser mais consonante ao patrimonialismo e à postura do estamento burocrático do que contrário a esses fenômenos. Nesse sentido, o eterno retorno pode não auxiliar na resolução do problema da viagem redonda brasileira.

Entretanto, é possível que o eterno retorno permita uma reinterpretação da ideia de “transvaloração dos valores”, não para negar os afetos e impulsos, porém, também não para os afirmar e atendê-los a qualquer custo. Talvez a saída seja uma espécie de "transvaloração dos afetos", em vez de uma "transvaloração dos valores" (como foi pensado por Nietzsche). Isso porque nem todos os impulsos são benéficos, a exemplo do impulso por inserir interesses pessoais em âmbitos que teriam de ser impessoais, o que Faoro reconhece como uma postura patrimonialista. São posturas negativas que podem ser prejudiciais tanto ao próprio indivíduo que as tem, como também - o que ocorre na maioria das vezes - às pessoas a sua volta e à toda a sociedade. Ao mesmo tempo, foi identificado, com base em pesquisa de Damásio, que o cérebro humano depende diretamente da sua parte relacionada às emoções para a tomada de decisões do ponto de vista ético, confirmando a ideia já tecida em Hume de que razão e afetos não são opostos, nem comparáveis, mas cada um atua em um campo específico. Os afetos e as emoções, portanto, estão diretamente atrelados à postura ética de um indivíduo. Com base na pesquisa de Damásio, estar destituído de emoções e afetos é o mesmo que estar incapaz de tomar decisões éticas. 
A partir das conclusões de Raymundo Faoro a respeito da viagem redonda no Brasil, a resolução do problema do patrimonialismo e do estamento burocrático brasileiros não é capaz de ocorrer apenas mediante reformas institucionais. É preciso uma mudança social do ponto de vista ético; e a ética, conforme demonstrado, tem a ver com afetos. Segundo a argumentação apresentada no Capítulo 02, há uma relação direta entre afetos e juízos de valor éticos. Nesse sentido, seria preciso uma transvaloração dos afetos, e não uma transvaloração dos valores conforme pensou Nietzsche, para resolver o problema do patrimonialismo e do estamento burocrático na sociedade brasileira. É preciso a construção de afetos que signifiquem a importância do outro, da coletividade e do público para cada indivíduo, e afetos estes que, nesse reconhecimento, não insiram o indivíduo como sobranceiro aos outros, à coletividade e à coisa pública, mas que o faça se sentir integrado a esse todo. Seria essa uma ideia geral de afeto - ou ao menos um esboço dela - que se opõe ao patrimonialismo e ao estamento burocrático, uma vez que é contrária à confusão do público com o privado e do predomínio deste nessa relação.

\section{REFERÊNCIAS}

ALMEIDA, Gabriel Bertin de. David Hume contra os contratualistas de seu tempo. Kriterion, Belo Horizonte, n. 115, pp. 67-87, jun. 2007. Disponível em: <https://www.scielo.br/pdf/kr/v48n115/a0548115.pdf>. Acesso em 07 fev. 2021.

BRITO, Leonardo Octavio Belinelli de. Os dilemas do patrimonialismo brasileiro: as interpretações de Raymundo Faoro e Simon Schwartzman. 1. ed. São Paulo: Alameda, 2019.

DUGUIT, León. Manual de derecho constitucional. Granada: Editorial Comares, S.L., 2005.

FAORO, Raymundo. Os donos do poder: formação do patronato político brasileiro. 5. ed. São Paulo: Globo, 2012.

HAUAISS, Antônio. Minidicionário Houaiss da língua portuguesa. 4. ed. rev. e aumentada. Rio de Janeiro: Objetiva, 2010.

HUME, David. Tratado da natureza humana. 2 ed. São Paulo. UNESP, 2009.

LIMA; Francisco Jozivan Guedes de. OLIVEIRA, Nythamar Hilario de. Emoção, juízo moral e razão: Damásio e a crítica do racionalismo ético. Veritas, Porto Alegre, v. 64, n. 2, abr./jun. 2019, e $\quad-34 \quad 220$. 20 Disponível 
$<$ https://revistaseletronicas.pucrs.br/ojs/index.php/veritas/article/view/34220>. Acesso em 07 fev. 2021.

LOEWENSTEIN, Karl. Teoría de la constitución. Barcelona - Caracas - México: Editorial Ariel, 1979.

MARCHESINI JUNIOR, Waterloo. Seu Raymundo, o "doutor democracia": vida e obra do imortal Raymundo Faoro. GEM/JM Editora: Curitiba, 2004.

MARTON, Scarlett. O eterno retorno do mesmo, "a concepção básica de Zaratustra". Cad. Nietzsche, Guarulhos/Porto Seguro, v. 37, n.2, pp. 11-46, jul./set. 2016.

MELO NETO, João Evangelista Tude de. 10 lições sobre Nietsche. Coleção 10 Lições. Petrópolis, RJ: Vozes, 2017.

NEVES, Marcelo. A constitucionalização simbólica. 3. ed. São Paulo: Editora WMF Martins Fontes, 2011.

NEVES, Marcelo. A crise do Estado: da modernidade central à modernidade periférica Anotações a partir do pensamento filosófico e sociológico alemão. In: Revista de Direito Alternativo 3. São Paulo: Acadêmica, 1994.

NEVES, Marcelo. Constituição e direito na modernidade periférica: uma abordagem teórica e uma interpretação do caso brasileiro. São Paulo: Editora WMF Martins Fontes, 2018.

NIETZSCHE, Friedrich. The Gay Science. New York: Cambridge University Press, 2001.

NIETZSCHE, Friedrich Wilhelm. Ecce Homo: Como se chega a ser o que se é. São Paulo: Editora Escala, 2013.

NUNES, Benedito. Filosofia contemporânea. 4. ed. Belém: ed.ufpa, 2019.

QUINTÃO, Thales Torres. A relação entre o (neo)patrimonialismo e a sociedade civil no caso Collor. Revista Habitus - IFCS/UFRJ, v. 9, n. 1, pp. 91-108, 2011. Disponível em: <https://revistas.ufrj.br/index.php/habitus/article/view/11347/8297>. Acesso em 15 dez. 2020.

REALE, Giovanni; ANTISERI, Dario. Filosofia: Idade Contemporânea, vol. 3. 2. ed. rev. e ampl. São Paulo: Paulus, 2018. Coleção Filosofia.

REZENDE, Maria José de. A substancialidade dos procedimentos oligárquicos no Brasil entre 1995 e 1998: as análises de Faoro. Caderno CRH, Salvador, v. 24, n. 61, p. 183-201, jan./abr. 2011. Disponível em: https://www.scielo.br/j/ccrh/a/DjjGRXQpbDyf99t3rtRhygc/abstract/?lang=pt $>$. Acesso em 06 fev. 2021.

SILVA, André Luiz Olivier da. Os limites da razão e um ceticismo mitigado. In: NEUTZLING, Inácio. David Hume e os limites da razão. Revista do Instituto Humanitas 
Unisinos - IHU On-Line, São Leopoldo, ed. 369, pp. 13-18, 15 ago. 2011. Disponível em: < http://www.ihuonline.unisinos.br/media/pdf/IHUOnlineEdicao369.pdf>. Acesso em 07 fev. 2021.

SILVA, Artur Stamford da. 10 lições sobre Luhmann. Coleção 10 Lições. Petrópolis, RJ: Vozes, 2016.

VIANNA, Luiz Werneck. Raymundo Faoro e a difícil busca do moderno no país da modernização. In: BOTELHO, André; SCHWARCZ, Lilia Moritz. Um enigma chamado Brasil: 29 intérpretes e um país. São Paulo: Companhia das Letras, 2009. 